\title{
ESTARIAM SATISFEITOS OS BENEFICIÁRIOS DO PROGRAMA MINHA CASA, MINHA VIDA? evidências empíricas em municípios do Estado de Minas Gerais
}

1- Vinicius de Souza Moreira*

Doutorando em Administração pelo Programa de Pós-Graduação do Departamento de Administração e Contabilidade da Universidade Federal de Viçosa (UFV), Brasil. vinicius.souza@ufv.br

http://lattes.cnpq.br/0747318824526243

\section{2- Suely de Fátima Ramos Silveira}

Doutora em Economia Aplicada pela Escola Superior de Agricultura Luiz de Queiroz da Universidade de São Paulo (ESALQ/USP), Brasil.

Professora do Programa de Pós-Graduação em Administração do Departamento de Administração e Contabilidade da Universidade Federal de Viçosa (UFV), Brasil.

sramos@ufv.br

http://lattes.cnpq.br/4041789153483476

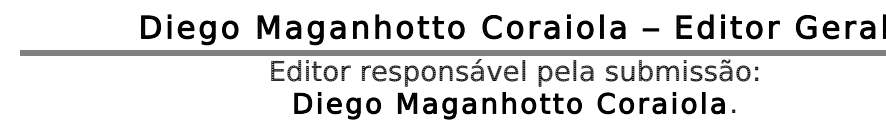

Artigo analisado via processo de revisão duplo cego (Double-b/ind).

Recebido em: 25/02/2017

Aprovado em: 28/07/2017

Última Alteração: 21/08/2017

\footnotetext{
* Contato Principal: Departamento de Administração e Contabilidade, Av. Peter Henry Rolfs s/n - Campus Universidade Federal de Viçosa - Viçosa/MG. CEP: 36570-900
} 


\title{
ESTARIAM SATISFEITOS OS BENEFICIÁRIOS DO PROGRAMA MINHA CASA, MINHA VIDA? EVIDÊNCIAS EMPÍRICAS EM MUNICÍPIOS DO ESTADO DE MINAS GERAIS
}

\section{RESUMO}

O Programa Minha Casa, Minha Vida (PMCMV) é a principal iniciativa governamental brasileira para reduzir o Déficit Habitacional do país que, pela sua realidade, requer adequada condução, evitando desvios de rotas que possam inviabilizá-la. Nesse sentido, o objetivo do artigo foi avaliar os resultados do PMCMV com base na percepção das famílias beneficiadas. O quadro teórico demonstra fundamento nos conceitos da avaliação de programas sociais e sua aplicação ao contexto habitacional. A investigação ocorreu em Minas Gerais, considerando amostra de 110 famílias distribuídas em oito municípios. Foram adotadas três categorias para execução da pesquisa: unidade habitacional, conjunto habitacional e entorno. Em relação a unidade habitacional, beneficiários de moradias horizontais mostraram-se mais satisfeitos; famílias numerosas exibiram satisfação inferior e a segunda fase do Programa foi melhor avaliada. Sobre o conjunto habitacional, beneficiários dos conjuntos verticais, com menos integrantes e de empreendimentos da segunda fase se revelaram mais satisfeitos. Quanto ao entorno, houve diminuição da satisfação quanto à infraestrutura e o acesso à cidade conforme aumento do tamanho familiar. A partir do contato com os beneficiários ficou nítida a importância social do PMCMV e a modificação promovida em suas vidas. É necessário, portanto, e com base nos pontos críticos levantados, continuar realizando correções no Programa para que as benfeitorias promovidas possam dirimir as desigualdades sociais.

\section{Palavras-chave}

Habitação; Avaliação; Políticas públicas; Satisfação.

\section{WILL THE BENEFICIARIES OF THE “MINHA CASA, MINHA VIDA" PROGRAM BE SATISFIED? EMPIRICAL EVIDENCE IN THE STATE OF MINAS GERAIS}

\begin{abstract}
The "Minha Casa, Minha Vida" Program (PMCMV) is the main Brazilian government initiative to remedy the country's housing deficit, which, due to its reality, requires adequate management, avoiding detours that could make it unfeasible. In this sense, the objective was to evaluate the PMCMV results based on the perception of the beneficiary families. The theoretical framework was based on the concepts of evaluation of social programs and their application to the housing context. The investigation occurred in Minas Gerais, considering a sample of 110 families distributed in eight municipalities. We adopted three categories: housing unit, housing complex and environment. In relation to the housing unit, beneficiaries of horizontal housing were more satisfied; large families showed lower satisfaction and the second phase of the Program was better evaluated. On the housing set, beneficiaries of the vertical groups, with less members and of enterprises of the second phase were more satisfied. As for the environment, there was a decrease in satisfaction with infrastructure and access to the city as family size increased. From the contact with the beneficiaries was clear the social importance of the PMCMV and the modification promoted in their lives. It is considered necessary, based on the critical points raised, to continue making corrections in the Program so that the promoted improvements can solve the social inequalities.
\end{abstract}

\section{Keywords}

Housing; Evaluation; Public policy; Satisfaction. 


\section{Introdução}

A carência de moradias, enquanto objeto de políticas públicas, voltou a ganhar evidência no Brasil nas duas primeiras décadas deste século. Como ilustração deste movimento, elementos de ordem política e institucional foram instaurados neste período, tais como: a inclusão da moradia como direito social na Constituição Federal (em 2000); a promulgação do Estatuto das Cidades (que trouxe a afirmação da função social da cidade e da propriedade); a criação do Ministério das Cidades (2003), que estruturou as secretarias nacionais ligadas às políticas urbanas, em espacial, à de habitação; o estabelecimento da Política Nacional de Habitação (2004), bem como a instituição do Sistema Nacional de Habitação (2005) e do Plano Nacional de Habitação (2007); e a criação de programas de envergadura para construção/requalificação de moradias como o Programa de Arrendamento Residencial (2001); o Programa de Aceleração do Crescimento (2007) e o Programa Minha Casa, Minha Vida (2009).

Dentre as ações outrora mencionadas, o foco deste atrigo recaiu sobre o Programa Minha Casa, Minha Vida (PMCMV), que até o ano de 2016 concluiu duas fases de atuação, sendo investidos cerca de $\mathrm{R} \$ 295$ bilhões; 4.219.366 unidades habitacionais contratadas; e, aproximadamente, 10,5 milhões de pessoas beneficiadas (Brasil, 2016). O PMCMV atua em modalidades subdivididas no eixo urbano e rural e segrega os participantes de acordo com a faixa de renda, que pode variar até 10 salários mínimos/mês. A finalidade deste estudo, portanto, centrou atenção no provimento habitacional às famílias de "interesse social", isto é, aquelas que possuem rendimento mensal inferior a três salários mínimos. Este público-alvo é o que possui maiores restrições de aquisição de moradia diretamente no mercado imobiliário e representa a maior parcela do Déficit Habitacional Brasileiro. O referido Déficit é uma medida criada pela Fundação João Pinheiro [ FJP] (2016) para dimensionar o nível de carência das moradias no país, sendo as variáveis consideradas para tanto, habitações precárias, coabitações familiares, moradias com ônus excessivo de aluguel e adensamento de moradores em domicílios alugados. No ano de 2014, 6,068 milhões de moradias (FJP, 2016) estavam sob essas condições.

Revestido das diretrizes que enfocam a diminuição das desigualdades em termos habitacionais, o conjunto de ações consoantes ao escopo do PMCMV são consequências das políticas públicas que buscam reduzir o Déficit Habitacional do país que, pela sua realidade, requer adequada condução, evitando gastos desnecessários e desvios de rotas que possam inviabilizar a ampliação destas iniciativas. Por tais razões, no âmbito do estudo das políticas públicas, há a análise e avaliação, que são essenciais para sociedade, uma vez que as demandas são crescentes e os recursos, escassos (Drumond, 2014). Frey (2000), reitera que a escassez na dotação de recursos públicos torna o ato de avaliar as políticas e programas públicos, tais como o PMCMV, imprescindível para a efetividade estatal. E, ainda sob este campo, Bryson, Patton e Bowman (2011) acrescentam que estudos avaliativos que focalizam a análise nos stakeholders têm ganhado relevância por questões práticas e éticas, sendo utilizada para melhorar a concepção e a implantação de instrumentos de avaliação e, ainda, para auxiliar na tomada de decisão. Destarte, a proposta desta investigação consistiu na avaliação dos resultados do Programa Minha Casa, Minha Vida, haja vista a percepção daquelas que são as mais afetadas pela intervenção: as famílias beneficiadas.

Autores como Moraes e Abiko (2006) argumentam que pesquisas de satisfação e/ou percepção dos moradores a respeito dos ambientes construídos têm fundamental importância nas avaliações de pós-ocupação, pois informações essenciais sobre os projetos podem ser capturadas. Ademais, trata-se de uma forma de inserir no processo avaliativo de um programa social o ponto de vista de um ator que raramente participa das etapas de mensuração de resultados (Lima, Formoso \& Escheveste, 2011; Reis, Silveira \& Moreira, 2015).

Em decorrência do anteriormente exposto, a presente pesquisa contribui para campo da avaliação de políticas públicas, incrementando o estoque de conhecimento da área, em especial, ao trazer evidências sobre os resultados de um programa social brasileiro. O estudo em tela dialoga com outras comunicações que trataram de medidas de desempenho de programas e projetos habitacionais de interesse social (experiências tanto nacionais quanto internacionais), tais como Ortiz e Doménech (2004); Marengo e Elorza (2010); Kowaltowski e Granja (2011); Brasil (2014); Hernández e Velásquez (2014); Morais, Carneiro e Barros Neto (2014); Moreira e Silveira (2015) e Reis et al. (2015). A partir do diálogo com a referida literatura foi possível desvelar um modelo analítico que compreendeu os principais produtos/resultados esperados de um programa social de habitação, nos moldes do estudado. Adicionalmente, houve a incorporação de características importantes do contexto do próprio PMCMV e, também, das famílias beneficiadas. Em razão disso, avança-se nas discussões sobre avaliação ao congregar às categorias de análise estabelecidas a priori (unidade habitacional, conjunto habitacional e entorno) elementos contextuais (atributos do Programa e das famílias) construindo, assim, um modelo avaliativo dinâmico, que captura nuances situacionais (que podem afetar nas percepções), o que permite análises comparativas. 
O artigo está estruturado em cinco seções, sendo a primeira esta introdução. A segunda dedica espaço para apresentar o embasamento teórico-empírico e foi subdividida em duas partes, uma a respeito da avaliação de programas sociais e a outra sobre a avalição no contexto dos programas habitacionais. A terceira apresenta a abordagem metodológica. A quarta, por sua vez, traz as discussões para os achados da pesquisa. A quinta e última parte encerra o artigo trazendo as considerações finais.

\section{Referencial Teórico}

O delineamento teórico do estudo buscou fundamento na Análise de Políticas Públicas, ou seja, na interpretação das causas e consequências da ação do governo na sociedade (Subirats, Knoepfel Larrue \& Varone, 2008). Sob essa perspectiva, as atenções foram focalizadas na avalição de programas sociais, entendendo suas definições, características e critérios bem como a relação com os programas e projetos habitacionais.

\subsection{Avaliação de Programas Sociais}

A atuação do governo diante dos problemas da sociedade se materializa por meio das políticas públicas. Tais ações ganham corpo a partir do estágio da formulação, o qual traz o marco regulatório das iniciativas. Destarte, as políticas públicas, depois de desenhadas, podem se desdobrar em planos, programas e projetos (Souza, 2006). O projeto consiste em um empreendimento planejado composto por atividades relacionadas, coordenadas e dirigidas ao alcance de objetivos específicos, em um local ou em várias localidades. O programa, por sua vez, é o conjunto de projetos e atividades que perseguem os mesmos objetivos. Assim, o plano constitui a soma desses programas e projetos e ordenam os objetivos gerais das intervenções (Cohen \& Franco, 2008; Morra-Imas \& Rist, 2009).

A ênfase do estudo foi em um programa social do governo federal, o "Minha Casa, Minha Vida", iniciativa destinada a subsidiar a construção de moradias para a população que tem restrições de acesso ao mercado imobiliário. Criado em 2009, o PMCMV é o principal responsável pela habitação enquanto alvo de políticas públicas no Brasil. Dessa forma, ao considerar sua importância para o desenvolvimento socioeconômico do país e para a redução das desigualdades sociais, é fundamental a elaboração e a utilização de medidas de desempenho capazes de expressar o grau de alcance das metas e objetivos estabelecidos. Logo, a quantificação ou qualificação de parâmetros que permitam às equipes gerenciais, dirigentes, políticos e cidadãos conhecerem e decidirem acerca dos arranjos governamentais, figura-se como atividade essencial ao cenário governamental (Brasil, 2004).

Em consonância a essas indicações, Rossi, Lipsey e Freeman (2004), argumentam que a aplicação de métodos de avaliação de programas sociais coincide com o crescimento e o aperfeiçoamento dos próprios métodos de pesquisa, bem como com as mudanças ideológicas, políticas e demográficas. Nesta direção, segundo Ramos e Schabbach (2012), a avaliação é uma ferramenta importante para melhorar a eficiência do gasto público, a qualidade da gestão e o controle social sobre a efetividade da ação do Estado.

Desse modo, o ato de avaliar compreende o processo de medição sistemática da operação e/ou dos resultados de um projeto, programa ou política, em relação ao desempenho, eficácia e impacto (ambos esperados ou não) tendo em vista os objetivos planejados (implícitos ou explícitos), com fins de contribuir para o aprimoramento das ações (Weiss, 1998; Rossi et al., 2004; Morra-Imas \& Rist, 2009). Ao incorporar elementos valorativos e de julgamento, a avaliação contempla aspectos qualitativos, não se confundindo com o mero acompanhamento dos atos governamentais (Ramos \& Schabbach, 2012). Por conseguinte, esta atividade engloba o estabelecimento de critérios, adoção de medidas de desempenho, a seleção de quais agentes estarão envolvidos e o momento de realização.

Diferentes critérios (ou tipologias) podem ser adotados para avaliar um programa social, sendo que variam de acordo com os objetivos assumidos: eficiência; eficácia; impacto (ou efetividade); sustentabilidade; análise custo-efetividade; satisfação do beneficiário e equidade (Unicef, 1990; Costa \& Castanhar, 2003; Subirats et al., 2008). A pesquisa focalizou a satisfação do beneficiário, sendo compreendida como a avaliação que mensura a "atitude do usuário em relação à qualidade do atendimento que está obtendo do programa" (Costa \& Castanhar, 2003, p.973). O destaque foi para a satisfação do beneficiário quanto aos resultados do PMCMV, entendidos aqui como os principais produtos entregues pela intervenção habitacional. 
Além do critério de mensuração daquilo que se pretende avaliar, é necessário o estabelecimento de medidas de desempenho. Na avaliação, o indicador é a unidade que permite medir o alcance de um objetivo específico (Cohen \& Franco, 2008). Assim, à luz do objetivo proposto, os indicadores são os principais instrumentos para verificar se a ampla gama de resultados dos programas foi satisfatória ou insatisfatória (Unicef, 2010). Januzzi (2005, p.138) reforça que os "indicadores apontam, indicam, aproximam, traduzem em termos operacionais as dimensões sociais de interesse". Deste modo, os indicadores foram construídos com base no desenho do Programa avaliado e em pesquisas correlatas, extraindo dos normativos e estudos científicos os principais elementos para apreciar a satisfação do beneficiário.

Definidos o critério e as medidas de mensuração, foi estabelecido o público-alvo da avaliação. Wu, Ramesh, Howlett e Fritzen (2010) explicam que a avaliação de políticas públicas se refere a todas as atividades empregadas para este fim e que sejam realizadas por distintos atores estatais e sociais, isto é, representantes governamentais ou não. Os autores denotam que podem participar dos processos os atores governamentais (políticos, governantes, burocratas) e não-governamentais (pesquisadores em universidades, empresas de consultoria, mídia). Para esta avaliação, o público foi o beneficiário do Programa. Na visão de Wu et al. (2010, p. 120), dentre os atores nãogovernamentais os "mais importantes são, obviamente, os usuários do serviço, que têm a experiência em primeira mão de como o programa em questão está funcionando na prática".

Na prática, os tipos de avaliação podem ser operacionalizados em conjunto e ocorrer antes, durante ou após a implementação dos programas. Com isso, de acordo com o momento de realização, a avaliação é classificada como: ex-ante, que ocorre anterior ao início da elaboração da proposta; de processo, realizada durante a execução do conjunto de atividades; e a ex-post, realizada ao final de uma etapa ou dada a finalização da intervenção como um todo (Cohen \& Franco, 2008). Por se tratar de uma avalição de satisfação quanto aos resultados do PMCMV, a medição sistemática realizada se enquadra no timming ex-post, pois ocorreu após a execução de todas as atividades exigidas para concluir a provisão habitacional nos municípios visitados.

Conforme Cohen e Franco (2008), a avaliação não deve ser entendida como uma atividade isolada e autossuficiente, pois faz parte do projeto de planejamento das políticas públicas, o que possibilita retroalimentação do processo político. Permite, ainda, analisar os resultados dos projetos, fornecendo condições de retificar as ações e reorientá-las em direção aos fins planejados. Assim compreendida, a avaliação auxilia na identificação de processos, resultados e impactos, permitindo comparar desempenhos, julgar, informar, dar visibilidade e propor alternativas para as políticas, programas e projetos sociais decorrentes das inciativas governamentais.

A próxima seção apresenta as características dos estudos avaliativos no campo habitacional, com destaque para literatura (brasileira e internacional) que tem dedicado seus esforços de pesquisa à questão.

\subsection{A Avaliação no Contexto dos Programas Habitacionais}

Os estudos que envolvem habitação e políticas públicas configuram um campo plural e multidisciplinar de pesquisas. As temáticas abrangem diferentes características, como a adequação técnica das casas produzidas com as especificações mínimas desejadas (Scheidt, Silva, Silva \& Hirota, 2010; Carraro \& Dias, 2014); a dinâmica do mercado imobiliário e os desdobramentos da especulação financeira/imobiliária que giram em torno dessa atividade (Soares, Carvalho, Ribeiro Filho \& Pinto, 2013); a relação entre os decisores, formuladores e demais atores envolvidos no âmbito das políticas (Bugs \& Reis, 2014); a integração da política habitacional com a gestão da política urbana (Silva, 2011), dentre outras. Comumente são empregadas pesquisas teóricoempíricas com enfoques quantitativos e qualitativos convergindo, principalmente, para estudos relacionados à avaliação, isto é, medição dos efeitos causados por projetos executados essencialmente pela administração pública municipal (Moreira, 2016).

Convém destacar que os estudos avaliativos se concentram na aplicação de distintos instrumentos da Avaliação Pós-Ocupação (APO) para aferir a qualidade das edificações produzidas. A APO, segundo Romero e Ornstein (2003), engloba uma série de métodos e técnicas direcionadas a diagnosticar fatores positivos e negativos do ambiente construído no decorrer do uso. Esta atividade, continuam os autores, deve investigar os fatores socioeconômicos, de infraestrutura e superestrutura urbanas, conforto ambiental, conservação de energia, fatores estéticos, funcionais e comportamentais, levando em consideração o ponto de vista dos avaliadores, projetistas, clientes e dos usuários. 
Nessa perspectiva, existem investigações como as de Scheidt et al. (2010) e Berr e Formoso (2012) que propuseram a avaliação de projetos e da qualidade dos processos construtivos de empreendimentos habitacionais de interesse social. Há, ainda, as pesquisas de Moraes e Abiko (2006) e Schäfer e Gomide (2014) que aplicaram a APO em conjuntos habitacionais para famílias de baixa renda. Outros pesquisadores buscaram compreender a relação da família beneficiária com a moradia construída, sublinhando aspectos subjetivos dos indivíduos e de seu ponto de vista (satisfação) a respeito dos ambientes edificados (Ortiz \& Doménech, 2004; Kowaltowski \& Granja, 2011; Hernández \& Velásquez, 2014).

Sobre o "Minha Casa, Minha Vida", especificamente, há de se comentar sobre a literatura que vem direcionando estudos a apreender o Programa em suas múltiplas particularidades e desdobramentos. A partir de buscas nas bibliotecas eletrônicas Scielo e Spell, para artigos que investigaram exclusivamente o PMCMV, foram identificadas 31 pesquisas no total. Ao realizar o agrupamento de tais textos, foram observados exemplos de estudos sobre: (a) os efeitos do Programa na produção do espaço e na paisagem das cidades (Thery, 2017; Rolnik et al., 2015; Moura, 2014); (b) as interações entre atores e os arranjos institucionais envolvidos na execução do PMCMV (Loureiro, Macário \& Guerra, 2015; Pequeno \& Rosa, 2016); (c) os impactos financeiros e econômicos do Programa no setor imobiliário (Silva \& Alves, 2014; Gonçalves Júnior, Dutra, Lopes \& Rodrigues 2014) e (d) a avaliação de resultados das intervenções em aspectos como a disponibilidade de comércio e serviço aos empreendimentos construídos (Vicentim \& Kanashiro, 2016) e a satisfação e percepção dos beneficiários quanto aos requisitos dos produtos gerados pelo PMCMV (Moreira \& Silveira, 2015; Reis et al., 2015; Aragão \& Hirota, 2016). Além dos referidos artigos, outras publicações foram materializadas em coletâneas: a primeira, organizada por Cardoso (2013), traz um conjunto de artigos, com experiências de várias partes do país, discutindo o PMCMV e seus efeitos territoriais, tendo em vista questões espaciais, econômicas e sociais; e a segunda, organizada por Amore, Shimbo e Rufino (2015), discute a avaliação do Programa em seis estados brasileiros, com atenção às experiências em capitais estaduais e regiões metropolitanas.

A breve incursão pela literatura mostra que os programas e projetos sociais em habitação, além do fomento à cadeia produtiva da construção civil e do setor imobiliário, têm como premissa principal a redução do Déficit Habitacional brasileiro. Assim, diante do conjunto de pesquisas ora apresentadas, o presente trabalho direciona o olhar à avaliação sob a perspectiva do beneficiário, inserindo elementos contextuais (atributos do Programa e das famílias) construindo, assim, um modelo avaliativo dinâmico, que captura nuances situacionais, o que permite análises comparativas.

Por essas razões, as avaliações desta natureza são direcionadas a medir as percepções daqueles que foram alvos diretos das iniciativas, de modo a obter resultados não só dos números alcançados em termos de redução de déficits, mas também quanto a satisfação em relação aos produtos entregues. Em particular, os estudos nessa perspectiva têm o potencial para auxiliar na compreensão de elementos da habitabilidade que, conforme Hernández e Velásquez (2014), referese às condições e a qualidade daquilo que se pode habitar. O conceito não se restringe apenas à moradia, apresentando, inclusive, estreita relação com a dimensão familiar (interna à habitação) e, também, com a vizinhança e a cidade (dimensões externas). Os autores assinalam, ainda, que é composta por elementos físicos (espaço, tamanho, infraestrutura, equipamentos e serviços urbanos, entre outros), e subjetivos (bem-estar, conforto e tranquilidade, identidade e privacidade, por exemplo).

Em complementariedade ao termo "habitabilidade", foi incorporado o entendimento do que venha ser a Habitação de Interesse Social (HIS). A HIS transcende a dimensão de produto, isto é, a visão estritamente física das moradias construídas, conforme a perspectiva de Abiko $(1995, \mathrm{p} .12)$ na qual é tida como "resultado de um processo complexo de produção com determinantes políticos, sociais, econômicos, jurídicos, ecológicos, tecnológicos".

Com isso, resultante do esforço analítico da literatura especializada e do corpo legislativo do Programa (Portaria n. 168, 2013; Caixa Econômica Federal [CEF], n.d.), foram identificados os principais produtos resultantes da provisão habitacional do PMCMV. E, para a concretização da avaliação de resultados, foram delimitadas as categorias e suas respectivas variáveis para a investigação com os beneficiários (Figura 1). 
Figura 1. Categorias da avaliação e suas características

\section{CATEGORIAS}

Unidade

Habitacional

Conjunto Habitacional

Entorno
FINALIDADE/DESCRIÇÃO

A proposta da categoria foi avaliar a satisfação dos beneficiários quanto aos resultados (de curto prazo) do Programa no que diz respeito a unidade habitacional. Foi segmentada nas subcategorias habitabilidade; segurança e aspectos construtivos e estéticos.

A habitabilidade é o atributo dos espaços construídos para satisfazer as necessidades objetivas e subjetivas dos indivíduos e grupos que os habitam (Ortiz \& Doménech, 2004; Hernández \& Velásquez, 2014). Conforme os conceitos orientadores para concepção de projetos de HIS (CEF, n.d) e as discussões de Hernández e Velásquez (2014), a habitabilidade abrangeu atributos relacionados à: funcionalidade (disposição dos cômodos; adaptabilidade; adequação ao mobiliário); tamanho; conforto ambiental (temperatura, privacidade, ruídos, ventilação); flexibilidade (possibilidades de alterações) e acessibilidade. Tais elementos possibilitam avaliar a qualidade do ambiente e do espaço interno (Kowaltowski \& Granja, 2011).

A segurança compreende aspectos relacionados à segurança estrutural, contra incêndios, intrusão (assaltos, roubos ou quaisquer tipos de vandalismo) e no uso e operação da unidade habitacional (CEF, s.d). Faz referência à situação de que o indivíduo e sua família se sentem seguros e que há o afastamento de riscos e perigos (Moreira \& Silveira, 2015; Reis et al., 2015). Engloba características socioculturais da convivência familiar (Kowaltowski \& Granja, 2011).

Os aspectos construtivos e estéticos dizem respeito ao nível de qualidade (solidez e durabilidade) dos principais materiais utilizados para a construção da moradia (Moreira \& Silveira, 2015; Reis et al., 2015): pisos, revestimento das paredes, portas, janelas, telhado, estrutura, instalações elétricas, instalações hidráulicas e a percepção quanto a aparência da edificação (Morais et al., 2014).

A finalidade da categoria consistiu na avaliação da satisfação dos beneficiários quanto aos resultados (de curto prazo) do Programa no que diz respeito ao conjunto habitacional. Foi decomposta nas subcategorias aspectos físicos e estéticos e infraestrutura urbana.

Os aspectos físicos e estéticos do conjunto habitacional correspondem aos elementos, em exigência ou não nos normativos, que compõe o empreendimento (Brasil, 2013; Moreira \& Silveira, 2015) tendo sido considerado áreas de lazer, áreas de convivência/reuniões, aparência e acessibilidade.

A infraestrutura urbana abrangeu o nível de qualidade (regularidade, funcionamento, manutenção) dos equipamentos e serviços urbanos que atendem às necessidades básicas do conjunto habitacional (Moreira \& Silveira, 2015; Reis et al., 2015): abastecimento de água; iluminação pública, esgotamento; coleta de lixo; lixeiras; escoamento de água; ruas; calçadas; sinal de telefonia e internet.

O escopo da categoria foi avaliar a satisfação dos beneficiários quanto aos resultados (curto prazo) do Programa no que diz respeito ao entorno e sua viabilização. Foi segmentada nas subcategorias infraestrutura urbana e acesso.

A infraestrutura urbana traz os principais elementos físicos que ligam o conjunto à cidade, com o intuito de verificar a satisfação dos beneficiários quanto a eles, quais sejam: ruas; calçadas; iluminação pública e ligação entre conjunto e cidade.

O acesso faz referência à distância, tempo e custo gastos para se chegar aos principais pontos da cidade (Moreira \& Silveira, 2015; Reis et al., 2015), tendo sido considerado: comércio/serviços básicos; áreas de lazer; transporte público; educação; saúde; assistência social e igrejas/templos religiosos.

Figura 2. Modelo analítico: categorias da avalição, satisfação e características contextuais

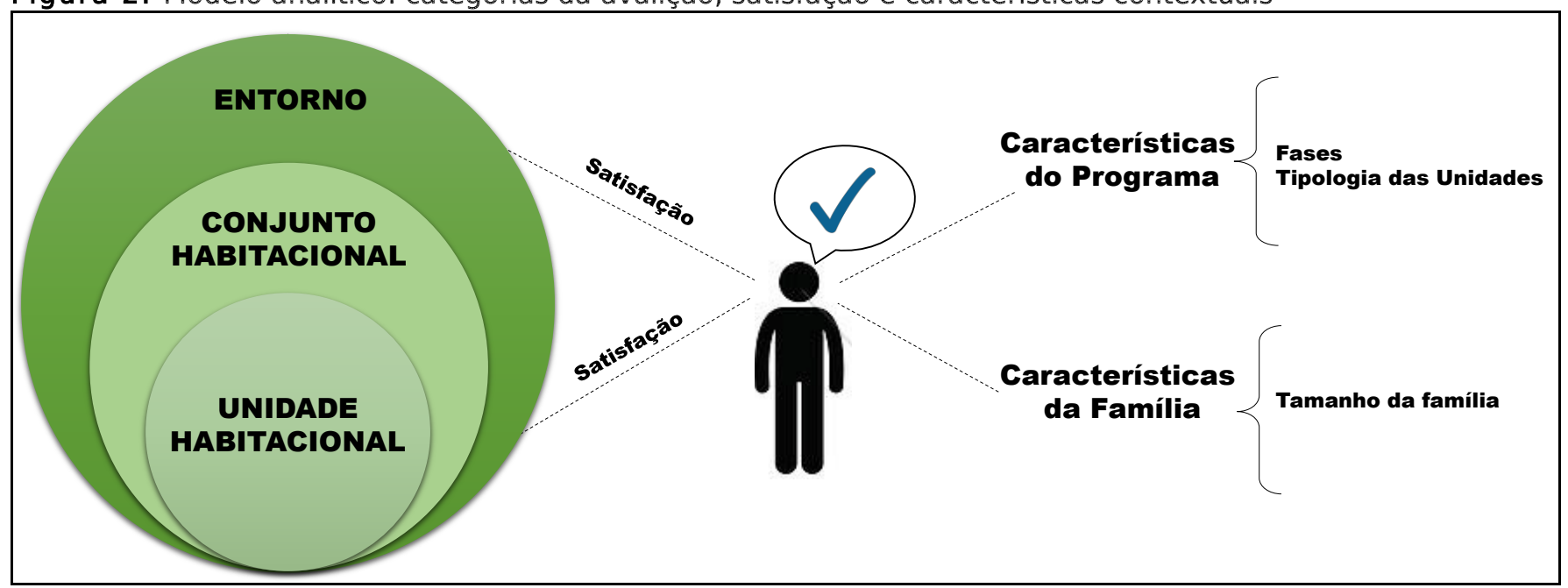

Fonte: elaboração própria. 
Estariam satisfeitos os beneficiários do programa minha casa, minha vida? Evidências empíricas em municípios do Estado de Minas Gerais

Em virtude do exposto, a proposta de discussão consistiu no alinhamento das medições quantitativas para avaliar a iniciativa habitacional tratada por esse estudo, levando em consideração a satisfação dos beneficiários (organizados em diferentes grupos conforme características do Programa e da família) em relação aos produtos do "Minha Casa, Minha Vida".

\section{Procedimentos Metodológicos}

\subsection{Características da Pesquisa}

A presente investigação se caracteriza como descritiva (Cervo \& Bervian, 2002) por expor atributos dos beneficiários do PMCMV, bem como suas percepções sobre os resultados do Programa. $\mathrm{E}$, no que se refere à natureza, a pesquisa é classificada como quantitativa, pois se configura pelo emprego de quantificação, tanto pelos dados coletados quanto pelo tratamento por meio de técnicas estatísticas (Richardson, 1999). No que tange ao processo de avaliação, correspondeu a análise dos resultados do PMCMV tendo como critério a satisfação dos beneficiários. Nesta avaliação, por sua vez, a ênfase foi no nível de satisfação das famílias acerca dos principais produtos entregues pela intervenção. Em relação ao timming, foi do tipo ex-post facto. O horizonte temporal de análise abrangeu o período de 2009 a 2014, que representa suas duas fases iniciadas e concluídas: o MCMV| (2009-2010) e o MCMV-II (2011-2014).

\subsection{Local de Estudo e Fonte de Dados}

A investigação ocorreu no estado de Minas Gerais. A escolha deste ente federativo balizou-se em particularidades como: (a) é o segundo estado mais populoso do país (Instituto Brasileiro de Geografia e Estatística [IBGE], 2010); (b) apresenta o segundo maior volume de moradias em situação de déficit: o estado possuía, em 2014, 529 unidades habitacionais nesta condição (FJP, 2016); e (c) no escopo do PMCMV, foi o 40 estado que mais contratou unidades habitacionais, somando 110.158 moradias durante as duas fases do Programa (Brasil, 2015).

Tabela 1:

Características das localidades visitadas

\begin{tabular}{|c|c|c|c|c|c|c|}
\hline Município & $\begin{array}{l}\text { U. } \text { Ha }^{\mathrm{a}} \\
\text { Contra- } \\
\text { tadas }\end{array}$ & $\begin{array}{c}\text { Investimento } \\
\text { Total (R\$) }\end{array}$ & $\begin{array}{c}\text { População } \\
\text { Total }\end{array}$ & $\begin{array}{l}\text { Tx. Urbani- } \\
\text { zação (\%) }\end{array}$ & $\begin{array}{c}\text { Déficit } \\
\text { Habitacional } \\
\text { Absoluto }\end{array}$ & $\begin{array}{l}\text { Renda per } \\
\text { capita }(R \$)\end{array}$ \\
\hline Alfenas & 660 & $30.795 .600,00$ & 73.774 & 93,8 & 1.836 & 820,70 \\
\hline Almenara & 500 & $29.000 .000,00$ & 38.775 & 81,9 & 1.617 & 510,61 \\
\hline Betim & 2.396 & $110.095 .674,36$ & 378.089 & 99,3 & 9.386 & 665,27 \\
\hline Ituiutaba & 2.523 & $120.867 .673,80$ & 97.171 & 95,8 & 3.402 & 831,25 \\
\hline Janaúba & 796 & $69.184 .000,00$ & 66.803 & 90,7 & 1.574 & 516,49 \\
\hline Juiz de Fora & 3.048 & $134.186 .463,02$ & 516.247 & 98,9 & 14.198 & $1.095,86$ \\
\hline Montes Claros & 3.033 & $158.347 .615,04$ & 361.915 & 95,2 & 9.618 & 695,77 \\
\hline Uberlândia & 4.172 & $170.984 .884,42$ & 604.013 & 97,2 & 17.961 & $1.032,98$ \\
\hline Total & 17.128 & $823.461 .910,64$ & 2.136 .787 & 94,1 & 59.592 & 771,12 \\
\hline Total MG & 110.158 & $4.475 .742 .840,30$ & 19.597 .330 & 85,3 & 519.493 & 537,73 \\
\hline
\end{tabular}

Nota. Fonte: Fundação João Pinheiro. (2016). Déficit Habitacional no Brasil. Recuperado em 20 abril, 2016 , de http://www.fjp.mg.gov.br/index.php/produtos-e-servicos1/2742-deficit-habitacional-no-brasil-3; Brasil. (2015). Sistema Eletrônico do Serviço de Informação ao Cidadão. Ministério das Cidades. Recuperado em 20 fevereiro, 2015, de http://www.acessoainformacao.gov.br.

a Significa "Unidades Habitacionais".

A seleção das localidades no estado teve como pauta, primeiramente, os critérios de recebimento de moradias pelo Programa, na modalidade direcionada à habitação urbana, financiada com recursos do Fundo de Arrendamento Residencial (FAR) e no período 2009-2014. A partir dessa primeira filtragem, dos 853 municípios de Minas Gerais, 67 estavam aptos a participarem da pesquisa (8\%). Tais municípios foram agrupados com o auxílio da Análise de Clusters ${ }^{1}$, em função das discrepâncias socioeconômicas entre eles (Costa, Ferreira, Braga \& Abrantes, 2012) e também por conta das limitações de tempo, recursos e acessibilidade. O referido procedimento resultou em quatro agrupamentos, sendo que em cada grupo foram escolhidos dois municípios, dentre aqueles que mais entregaram unidades habitacionais. Esta opção adveio do entendimento de que a maior quantidade de casas entregues expressaria maior experiência e complexidade na condução do Programa, o que traria maiores possibilidades para exploração no estudo de campo. Além disso, esta 
decisão levou em consideração as limitações de tempo e recursos e o fator acessibilidade para condução da pesquisa. Assim, todo este processo resultou na determinação de 08 municípios (conforme mesorregiões): Alfenas (Sul/Sudoeste de Minas); Almenara (Jequitinhonha); Betim (Metropolitana de Belo Horizonte); Ituiutaba e Uberlândia (Triângulo Mineiro/Alto Paranaíba); Janaúba e Montes Claros (Norte de Minas); e Juiz de Fora (Zona da Mata). Informações representativas dos municípios visitados encontram-se na Tabela 1.

Para permitir a visualização dos referidos municípios e sua localização no território de Minas Gerais, foi elaborada a Figura 3.

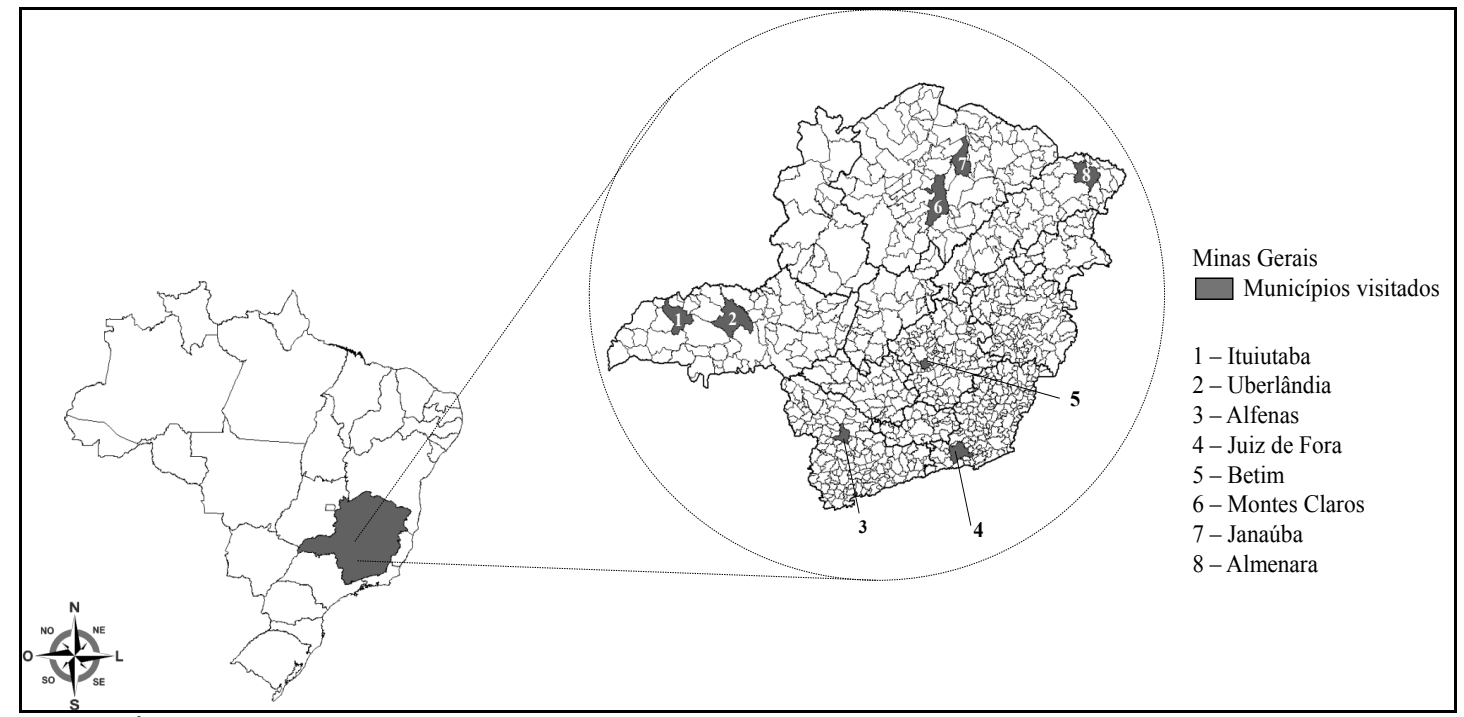

Figura 3. Municípios selecionados para estudo in loco

Fonte: elaboração própria tendo como auxílio o software TabWin.

Em cada localidade, o público-alvo da pesquisa compreendeu os beneficiários do Programa contemplados com unidades habitacionais no horizonte temporal de 2009 a 2014 . Ou seja, o indivíduo-foco para a investigação foi aquele que participou de todo o processo de seleção do PMCMV e foi designado para o recebimento da casa. E para a determinação do número de beneficiários abordados, de forma que fossem representativos diante dos oito municípios visitados, baseou-se no cálculo amostral para população finita, conforme exposição de Triola (2005, p.275). Para este equacionamento, a população $(N)$ correspondeu ao número total de beneficiários nas localidades selecionadas, sendo esse número traduzido pelo montante de unidades habitacionais entregues (01 unidade habitacional $=01$ beneficiário, sendo 17.498 nos oito municípios). Além disso, foi escolhido nível de confiança $(\sigma)$ de $95 \%$ (igual a 1,96); probabilidade de ocorrência e não ocorrência do fenômeno $(p ; q)$ de 0,5 ; e erro amostral $(\varepsilon)$ de $10 \%^{2}$. A aplicação deste raciocínio é apresentada na Equação 1 e resultou na amostra mínima de 96 beneficiários.

$$
\begin{gathered}
\mathrm{n}=\frac{\sigma^{2} \times \mathrm{p} \times \mathrm{q} \times \mathrm{N}}{\varepsilon^{2}(\mathrm{n}-1)+\left(\sigma^{2} \times \mathrm{p} \times \mathrm{q}\right)} \\
\mathrm{n}=\frac{1,96^{2} \times 0,5 \times 0,5 \times 17.163}{0,1^{2}(17.498-1)+\left(1,96^{2} \times 0,5 \times 0,5\right)}=96 \text { beneficiários }
\end{gathered}
$$

Como a população correspondeu ao número de beneficiários e este montante varia entre as localidades, foi realizada a distribuição das aplicações de questionários em cada município. O critério escolhido para tanto foi o número de unidades habitacionais entregues, uma vez que essa variável é representativa do número de indivíduos contemplados pelo Programa e possibilitou a distribuição dos respondentes conforme a participação de cada município na população total de beneficiários. $\mathrm{Na}$ Tabela 2, além desta distribuição, apresenta-se o total de aplicações, evidenciando que este montante superou a amostra pré-determinada.

Para a abordagem com os beneficiários, fez-se uso do método survey que envolve a coleta de informações que podem variar entre crenças, opiniões e atitudes (Hair, Anderson, Tatham \& Black, 2005) para um número mais ampliado de indivíduos. O instrumento de coleta de dados empregado foi o questionário estruturado com questões binárias, de múltipla escolha e outras associadas a escala do tipo Likert em um intervalo de 05 pontos (sendo 01 = muito insatisfeito; 02 = insatisfeito; 03 = indiferente; 04 = satisfeito; 05 = muito satisfeito). O questionário contou com dois blocos de perguntas: o primeiro para caracterização do perfil dos entrevistados e de sua família e o segundo 
para mensurar a satisfação nas três categorias avaliadas, unidade habitacional, conjunto habitacional e entorno.

Tabela 2:

Distribuição e aplicações dos questionários em relação a amostra

\begin{tabular}{lcccc}
\hline \multicolumn{1}{c}{ Município } & Unidades Entregues & Percentual de distribuição & Amostra Distribuída & Aplicações \\
\hline Alfenas & 854 & $5 \%$ & 05 & 10 \\
\hline Almenara & 500 & $3 \%$ & 03 & 08 \\
\hline Betim & 2.396 & $14 \%$ & 13 & 13 \\
\hline Ituiutaba & 2.438 & $14 \%$ & 13 & 13 \\
\hline Janaúba & 1.268 & $7 \%$ & 07 & 11 \\
\hline Juiz de Fora & 2.980 & $17 \%$ & 16 & 16 \\
\hline Montes Claros & 2.903 & $17 \%$ & 16 & 16 \\
\hline Uberlândia & 4.159 & $24 \%$ & 23 & 110 \\
\hline Total & 17.498 & $100 \%$ & 96 & \\
\hline
\end{tabular}

Nota. Fonte: resultados da pesquisa.

a Razão entre o total de unidades entregues nos oito municípios e unidades entregues em cada município.

Figura 4. Resumo da estratégia da pesquisa de campo

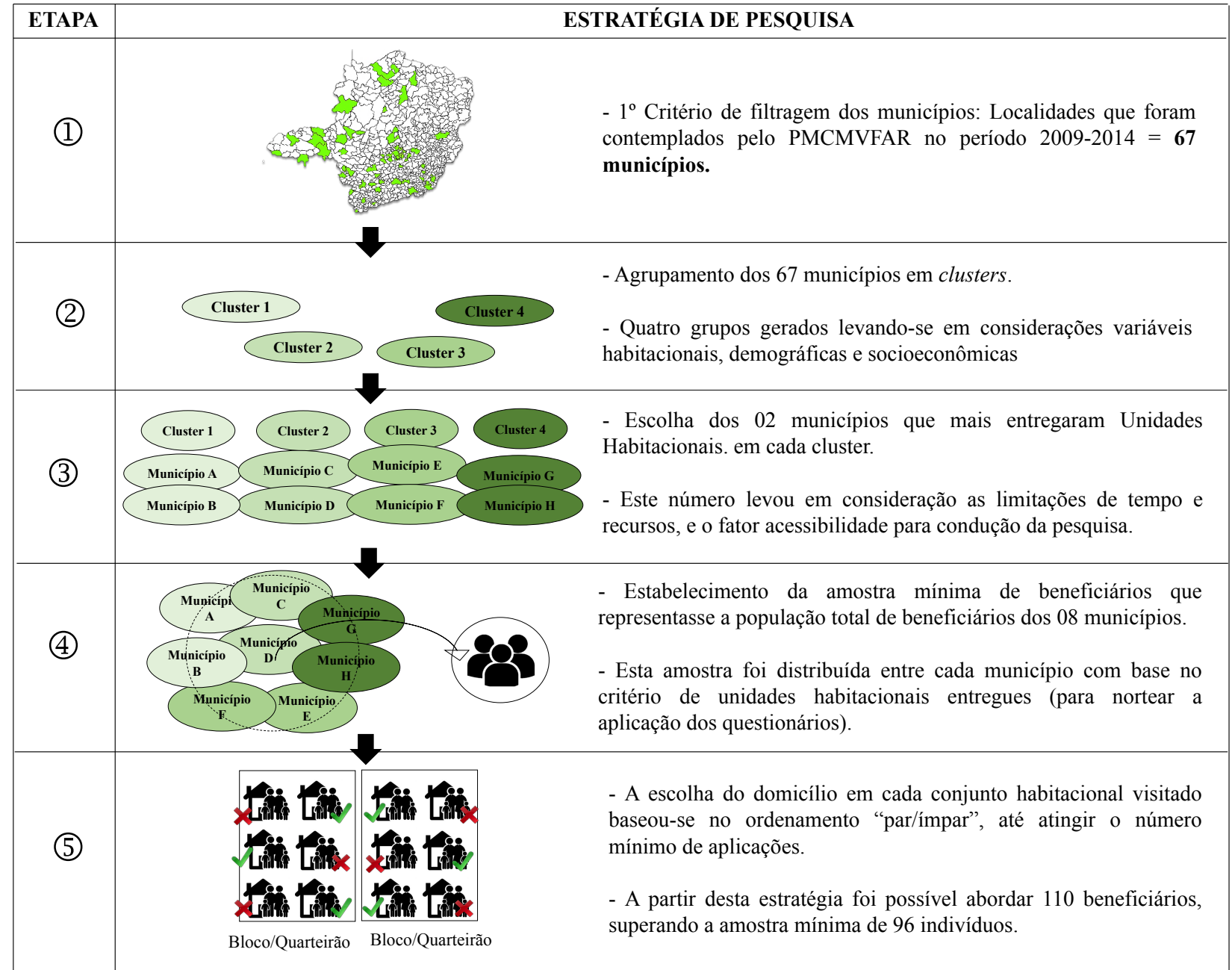

Fonte: elaboração própria.

A condução da pesquisa com os beneficiários ocorreu por meio da entrevista pessoal e contou com o apoio de gestores públicos e lideranças locais como facilitadores no acesso aos conjuntos habitacionais. As aplicações dos questionários aconteceram nos próprios residenciais, o que permitiu conhecer os conjuntos e aferir informações captadas a partir de observações e vivências. Tais dados foram registrados sob a forma de diário de campo, para utilização nas análises e discussões. E, como os empreendimentos visitados foram construídos sob a forma horizontal (casas térreas) ou vertical (apartamentos), a escolha dos domicílios teve como critério o 
ordenamento "par/ímpar". Isto é, em um bloco de apartamentos ou quarteirão eram abordadas apenas as unidades pares e no outro somente as ímpares, e assim sucessivamente até atingir o número de respondentes mínimos necessários.

De forma a sumarizar e organizar o percurso metodológico para condução da pesquisa de campo, é apresentada a Figura 4.

\subsection{Técnicas de Análise}

A intenção do estudo foi averiguar se haveria diferenças na satisfação dos indivíduos de acordo com as condições: (a) tipologia do empreendimento (segmentando os beneficiários em dois grupos, os contemplados com unidades verticais ou horizontais) e (b) fase do Programa (subdividindo os respondentes, à época do recebimento das moradias, no MCMV-I ou MCMV-II), ambos para incorporar características específicas ao PMCMV; e quanto o (c) tamanho da família (dividindo-os em três grupos, sendo "de até 02 pessoas na família"; "de 03 a 05 pessoas"; e "acima de 06 moradores"), para mensurar a percepção de acordo com as variações no número de integrantes nas moradias. O entendimento foi de que esses agrupamentos têm a possibilidade de trazer diferentes posicionamentos e auxiliar a interpretação das satisfações dos beneficiados quanto aos principais produtos e resultados do Programa, além de permitir análises comparadas. Isto posto, fez-se uso de ferramentas estatísticas, sendo que as técnicas adotadas foram:

(a) Análise Exploratória dos Dados, como forma de expor e analisar o comportamento geral das variáveis, utilizando técnicas da estatística descritiva (média e desvio padrão) e distribuição de frequências (absoluta e relativa);

(b) Alfa de Cronbach, para verificar a confiabilidade das subcategorias nas quais as variáveis componentes são fortemente correlacionadas (Hair et al., 2005). O Alfa de Cronbach permite valores no intervalo de zero a um, sendo que valores baixos indicam que os itens utilizados na escala não medem adequadamente a categoria (Hair et al., 2005). Há autores que, para um instrumento ou teste ser classificado como tendo confiabilidade apropriada, determinam que o alfa deva ser pelo menos 0,7. Em alguns cenários em ciências sociais, alfa de 0,6 é aceitável, desde que os resultados sejam interpretados com cautela (Maroco \& Garcia-Marques, 2006);

(c) Escala Somada, técnica que permite que várias afirmações sejam somadas para formar um escore total para uma (sub)categoria (Hair et al., 2005) e admitir a comparação entre grupos; e,

(d) Testes de médias, tais como teste $t$ para amostras independes e teste ANOVA. Esses testes comparam o comportamento de valores médios (aqui entendidos como o escore total médio de satisfação em cada categoria) dada a sua distribuição em grupos. O teste $t$ é aplicável quando se compara valores entre dois grupos (beneficiários da fase I e da II, por exemplo), e o ANOVA é adequado para comparações quando se tem mais de três agrupamentos (no caso, beneficiários segmentados em três composições familiares) (Pestana \& Gageiro, 2005).

\section{Resultados e Discussões}

Os resultados foram subdivididos de acordo com as categorias estabelecidas e que englobam os principais produtos do Programa "Minha Casa, Minha Vida". Destarte, a satisfação dos beneficiários é apresentada, primeiramente, quanto à unidade habitacional; depois, no que diz respeito ao conjunto habitacional; e, por fim, no que tange ao entrono. Ao final, há a compilação geral dos principais achados da investigação.

Apresenta-se, incialmente, a caracterização dos entrevistados e de suas famílias, como forma de caracterizar a amostra de indivíduos estudados. O perfil dos beneficiários apresentou os seguintes atributos: a maioria era mulher $(83 \%)$, de baixa escolaridade $(66 \%)$, solteiras (54\%), com rendimento mensal de até 01 salário mínimo (77\%), originário do recebimento de benefícios sociais e a realização de trabalho informal (66\%) e com idade média de 40 anos. Um dado interessante é que $38 \%$ dos entrevistados declararam que a única fonte de rendimento familiar advinha de benefícios sociais, com destaque para o Bolsa Família. Tal informação corrobora com a similaridade entre os públicos-alvo dos dois Programas, ou seja, mulheres em situação de vulnerabilidade. As famílias, por sua vez, tinham em média 04 membros, com maior frequência de crianças (28\%) e adultos (48\%). Identificou-se baixo percentual de idosos $(6 \%)$ e de núcleos familiares com algum integrante com deficiência física (9\%). A caracterização, tanto do respondente quanto de sua família, 
Estariam satisfeitos os beneficiários do programa minha casa, minha vida? Evidências empíricas em municípios do Estado de Minas Gerais

aproxima-se às de outras pesquisas de satisfação do PMCMV, como o estudo nacional do IPEA (Brasil, 2014) e de Morais et al. (2014), no estado do Ceará.

Tabela 3:

Satisfação dos beneficiários em cada grupo e subcategorias da unidade habitacional

\begin{tabular}{|c|c|c|c|c|c|c|c|c|c|c|}
\hline \multirow{2}{*}{\multicolumn{2}{|c|}{ Grupos/Subcategoria }} & \multicolumn{3}{|c|}{ Habitabilidade } & \multicolumn{3}{|c|}{ Segurança } & \multicolumn{3}{|c|}{$\begin{array}{c}\text { Aspectos construtivos e } \\
\text { estéticos }\end{array}$} \\
\hline & & Média & $\begin{array}{l}\text { Desv. } \\
\text { Padrão }\end{array}$ & $\begin{array}{l}\text { Teste de } \\
\text { Média }\end{array}$ & Média & $\begin{array}{l}\text { Desv. } \\
\text { Padrão }\end{array}$ & $\begin{array}{l}\text { Teste de } \\
\text { Média }\end{array}$ & Média & $\begin{array}{l}\text { Desv. } \\
\text { Padrão }\end{array}$ & Teste \\
\hline \multirow{2}{*}{ Tipologia } & Horizontal & 3,72 & 0,69 & \multirow{2}{*}{$0,000 *$} & 3,07 & 0,93 & \multirow{2}{*}{$0,340 * *$} & 3,88 & 0,69 & \multirow{2}{*}{$0,000 *$} \\
\hline & Vertical & 3,31 & 0,72 & & 2,92 & 0,70 & & 3,36 & 0,69 & \\
\hline \multirow{2}{*}{$\begin{array}{c}\text { Fase do } \\
\text { Programa }\end{array}$} & Fase I & 3,10 & 0,75 & \multirow{2}{*}{$0,000 *$} & 3,18 & 0,70 & \multirow{2}{*}{$0,310 * *$} & 3,44 & 0,70 & \multirow{2}{*}{$0,003^{*}$} \\
\hline & Fase II & 3,79 & 0,57 & & 2,87 & $\begin{array}{r}0,88 \\
*\end{array}$ & & 3,75 & 0,73 & \\
\hline \multirow{4}{*}{$\begin{array}{c}\text { Tamanho } \\
\text { da } \\
\text { Família } \\
\end{array}$} & Até 2 pessoas & 3,68 & 0,58 & \multirow{3}{*}{$0,032 *$} & 2,88 & 0,89 & \multirow{3}{*}{$0,300 * *$} & 3,77 & 0,63 & \multirow{3}{*}{$0,006^{*}$} \\
\hline & Entre 3 a 5 & 3,58 & 0,73 & & 3,15 & 0,87 & & 3,72 & 0,72 & \\
\hline & Acima de 6 & 3,15 & 0,79 & & 2,63 & 0,37 & & 3,18 & 0,73 & \\
\hline & Ifa de Cronbach & & 0,893 & & & 0,608 & & & 0,801 & \\
\hline
\end{tabular}

Nota. Dados obtidos na aplicação de questionários com escala do tipo Likert de 05 pontos, sendo 01 a pontuação mínima e 05 corresponde a pontuação máxima. Fonte: resultados da pesquisa.

${ }^{a}$ O Alfa de Cronbach valida a formação das subcategorias por apresentar valores superiores a 0,60.

* valores significativos ao nível de 5\%; **Não significativo.

No que tange à tipologia das unidades habitacionais, os testes de médias assinalaram que houve diferenças para os grupos estabelecidos no que concerne à satisfação quanto a habitabilidade e aspectos construtivos/estéticos. Ademais, nota-se que o nível médio de satisfação foi superior para as famílias contempladas com moradias horizontais, nos permitindo inferir que os beneficiados pelas casas sob esta tipologia estão mais satisfeitos do que os contemplados com apartamentos. Fatores que podem explicar a diferenciação fazem alusão ao fato de que nos apartamentos elementos da habitabilidade (possibilidade de alterações, ruídos/barulhos, tamanho área de serviço e temperatura) e dos aspectos construtivos e estéticos (qualidade das portas e janelas, dos pisos e revestimento das paredes) obtiveram avaliações inferiores.

E, sobre essa diferenciação é pertinente, mesmo que superficialmente, comentar sobre a (necessidade de) verticalização no espaço urbano nacional. De acordo com a análise de Oliveira (2013), a verticalização ${ }^{3}$ urbana brasileira é um processo que não está mais restrito às metrópoles e grandes cidades e está presente também nas cidades médias e pequenas (maioria das que foram visitadas pela pesquisa). O processo de verticalização no Brasil é discutido na literatura e confronta distintas opiniões. A controvérsia sobre essa forma de morar é marcada por aspectos positivos e negativos, assim como a existência de críticos e defensores. Os teóricos comentam sobre atributos técnicos, comportamentais, simbólicos e ambientais desse fenômeno. Ramires (1998), por sua vez, compila as características de tais estudos. De um lado, lança-se luz para uma vertente mais crítica, na qual autores advogam que o espaço urbano sofre alterações na estrutura interna da cidade, em sua estrutura social e no valor e uso do solo urbano, aumentando-o. Afeta, também, a dinâmica de acumulação/reprodução do capital no setor da construção civil e do mercado imobiliário, tornando-o excludente. Além disso, há a subordinação da legislação urbana aos interesses de determinados grupos que produzem o espaço urbano. Por outro lado, ainda comenta Ramires (1998), é uma questão também de modernidade, sendo que a verticalização é um fato típico dos tempos modernos, representa uma revolução na forma de construir e há utilização de menos espaço urbano para provimento das moradias.

Em relação ao PMCMV, Soraggi e Mendonça (2013), analisando a região metropolitana de Belo Horizonte, destacam que ocorrem transformações significativas nos padrões tradicionais de uso e ocupação do solo, principalmente nas periferias, em função da introdução da tipologia vertical, uma vez que nesses territórios ela inexistia anteriormente. Essas transformações podem implicar, consequentemente, na insatisfação com a unidade habitacional por efeitos da mudança considerável da configuração construtiva da moradia e as posteriores implicações na ocupação e no convívio familiar.

Diante da situação analisada, conforme as características dos municípios brasileiros, a verticalização tende a ser uma diretriz necessária, talvez por dois motivos: a ausência de terras bem localizadas para horizontalização e o custo que se incorre, pois em determinada área é possível 
alocar número maior de apartamentos do que de casas horizontais. Além do ônus do ponto de vista de quem promove a habitação, há de se considerar os custos que incidem na cidade e na administração pública local, responsável pelo ordenamento urbano. A horizontalização necessita de áreas maiores e a expansão dos limites urbanos pode trazer prejuízos ambientais, devido às necessidades de provimento e manutenção de infraestrutura e equipamentos públicos, além de influenciar na mobilidade, pois o assentamento residencial em novas áreas irá requerer linhas transporte público, por exemplo.

Foi possível observar, com isso, a existência de ambos pontos de vista na situação estudada. Identificou-se o predomínio dos interesses daqueles que detém o capital urbano, mas também se verificou a intenção de otimização do espaço. Portanto, por razões como as evidenciadas, é fundamental ressaltar a importância da associação das políticas habitacional e urbana. Este aspecto é destacado por Maricato (2009) que discute, justamente, a ausência de articulação do PMCMV com a política urbana, o que faz necessário pensar as ações em conjunto, tendo uma visão micro, na tentativa de observar as percepções das famílias (que se mostraram menos satisfeitas ao serem contempladas com unidades habitacionais verticais), mas também a visão macro, no sentido de que é o cenário urbano que arcará com possíveis danos e/ou prejuízos de ações mal planejadas.

No que tange à fase do Programa, constatou-se que os avanços e inovações proporcionadas nas características das unidades refletiram em melhores satisfações: a habitabilidade e os aspectos construtivos/estéticos foram melhor avaliados pelos beneficiários da segunda fase. Os resultados dos testes de médias confirmam essa avaliação ao apontarem para diferenciação dos grupos. Entre as fases, todas as variáveis relacionadas a I foram inferiores a II, no que diz respeito às subcategorias em análise. Atenção deve ser observada em propriedades como acessibilidade; adequação ao mobiliário e disposição dos cômodos (relacionadas à habitabilidade), que registraram as maiores variações. Além desses, portas e janelas, revestimento das paredes e telhado (pertencentes aos aspectos construtivos e estéticos) registraram incrementos positivos na satisfação média.

E, sobre o tamanho da família, notou-se satisfação inferior nas unidades que abrigam maior número de integrantes no núcleo familiar em relação à habitabilidade e aos aspectos estéticos e construtivos. Para as famílias compostas por grupos de até 02 pessoas e entre 03 a 05 pessoas não houve significância estatística. A diferenciação se deu ante àquelas com mais de 06 integrantes. Resultado esperado, por entender que numa unidade habitacional configurada da forma pela qual o Programa indica (sala, cozinha, banheiro, dois quartos e área de serviço), a densidade de moradores prejudica, principalmente, a habitabilidade dos familiares. As variáveis que mais se destoaram foram as de adequação ao mobiliário; privacidade; ruídos/barulhos; tamanho da cozinha; tamanho da sala; tamanho do banheiro; tamanho dos quartos (que representam os aspectos da habitabilidade); e estrutura da construção; instalações elétricas e instalações hidráulicas (sobre os elementos construtivos e estéticos). No levantamento nacional, essa situação também é comentada, uma vez que se identificou que as famílias beneficiadas pelo PMCMV são relativamente populosas, o que leva ao adensamento na moradia (Brasil, 2014).

Optou-se por comentar sobre a segurança, em especial, porque as diferenças entre satisfações médias para a subcategoria, em todos os grupos estabelecidos, não foram significativas. Isto é, seja em tipologias diferentes, fases do Programa ou em distintas composições familiares, os beneficiários registraram percepções similares. A segurança, nos termos aqui avaliados, envolveu duas situações: a estrutural e a quanto a intrusão (e também relacionada à vizinhança). No primeiro caso, as médias foram satisfatórias, até mesmo porque os projetos dependem da aprovação de corpo de bombeiros e engenheiros. Além disso, as especificações do Programa são rígidas quanto a estrutura (logo, em média, os beneficiários exibiram satisfação quanto a segurança de suas estruturas domiciliares). No entanto, do ponto de vista de segurança pública (proteção quanto a intrusão, violência e criminalidade) foi um problema recorrentemente relatado pelas famílias, registrando as menores avaliações. Resultados similares foram encontrados na pesquisa nacional (Brasil, 2014) e em investigações direcionadas a contextos específicos, como no Ceará (Morais et al., 2014) e Minas Gerais (Moreira \& Silveira, 2015; Reis et al., 2015), todas sobre empreendimentos do PMCMV. Beneficiários de outros programas habitacionais também apresentaram percepções semelhantes, a exemplo da investigação de Kowaltowski e Granja (2011), em Campinas-SP.

A respeito disso, acredita-se que esse aspecto da segurança transcende à provisão habitacional e requer diálogo com outras políticas públicas na tentativa de promover sua resolução. A precariedade na segurança pública é um equacionamento maior que os governantes precisam resolver. Todavia, um primeiro passo é dado: provimento de moradias para famílias com necessidades imediatas, inserindo-as em um local que as traz abrigo e proteção contra intempéries. Porém, as cidades brasileiras, de modo geral, já possuem seus índices de violência urbana 
Estariam satisfeitos os beneficiários do programa minha casa, minha vida? Evidências empíricas em municípios do Estado de Minas Gerais

(Kowaltowski \& Granja, 2011), criminalidade, roubos/furtos, utilização de entorpecentes, sendo que os residenciais construídos pelo PMCMV não estão imunes a esses acontecimentos.

\subsection{Satisfação dos Beneficiários Quanto ao Conjunto Habitacional}

Os olhares, agora, recaem sobre o conjunto habitacional, isto é, os aglomerados de unidades habitacionais, comumente denominados de "residenciais". Para esse produto gerado pelo Programa, a análise foi realizada quanto a infraestrutura urbana e aos aspectos físicos e estéticos. Do ponto de vista da satisfação dos beneficiários, os resultados podem ser visualizados na Tabela 4.

Tabela 4:

Satisfação dos beneficiários em cada grupo e subcategoria do conjunto habitacional

\begin{tabular}{|c|c|c|c|c|c|c|c|}
\hline \multirow{2}{*}{\multicolumn{2}{|c|}{ Grupos/Subcategoria }} & \multicolumn{3}{|c|}{ Aspectos físicos e estéticos } & \multicolumn{3}{|c|}{ Infraestrutura urbana } \\
\hline & & \multirow{2}{*}{$\begin{array}{c}\text { Média } \\
2,62 \\
\end{array}$} & \multirow{2}{*}{$\begin{array}{c}\text { Desvio Padrão } \\
0,63\end{array}$} & \multirow{3}{*}{$\begin{array}{l}\text { Teste de } \\
\text { Médias } \\
0,270 * *\end{array}$} & \multirow{2}{*}{$\begin{array}{c}\text { Média } \\
4,05 \\
\end{array}$} & \multirow{2}{*}{$\begin{array}{c}\text { Desvio Padrão } \\
0,47\end{array}$} & \multirow{2}{*}{$\begin{array}{l}\text { Teste de } \\
\text { Médias }\end{array}$} \\
\hline \multirow{2}{*}{ Tipologia } & Horizontal & & & & & & \\
\hline & Vertical & 2,79 & 0,96 & & 3,51 & 0,64 & $0,000^{*}$ \\
\hline \multirow{2}{*}{ Fase do Programa } & Fase I & 2,62 & 0,80 & \multirow[b]{2}{*}{$0,350 * *$} & 3,61 & 0,66 & \multirow{2}{*}{$0,002^{*}$} \\
\hline & Fase II & 2,76 & 0,81 & & 3,90 & 0,56 & \\
\hline \multirow{3}{*}{$\begin{array}{l}\text { Tamanho da } \\
\text { Família }\end{array}$} & $\begin{array}{l}\text { Até } 2 \\
\text { pessoas }\end{array}$ & 2,93 & 0,77 & \multirow{3}{*}{$0,087 * *$} & 3,82 & 0,71 & \multirow{3}{*}{$0,807 * *$} \\
\hline & Entre 3 a 5 & 2,73 & 0,84 & & 3,80 & 0,59 & \\
\hline & Acima de 6 & 2,40 & 0,66 & & 3,70 & 0,63 & \\
\hline
\end{tabular}

Nota. Dados obtidos na aplicação de questionários com escala do tipo Likert de 05 pontos, sendo 01 a pontuação mínima e 05 corresponde a pontuação máxima. Fonte: resultados da pesquisa.

${ }^{a}$ O Alfa de Cronbach valida a formação das subcategorias por apresentar valores superiores a 0,60.

* valores significativos ao nível de $5 \%$; **Não significativo.

A subcategoria aspectos físicos e estéticos obteve baixas médias de satisfação nos três grupos estabelecidos para análise (todos os valores inferiores a 3,0 pontos) e os testes de médias demostraram que não houve diferenciação entre as avaliações. Ou seja, independente da tipologia das unidades, fase e tamanho da família, a avaliação quanto a este atributo foi insatisfatória. Além disso, da fase I para a II esperava-se que inovações incorporadas ao Programa poderiam melhorar as avaliações, o que não foi confirmado estatisticamente. As variáveis áreas de lazer e áreas de convivência, nos três grupos, foram as que, em média, geraram os maiores níveis de insatisfação.

As explicações para tais comportamentos advêm das observações nos conjuntos habitacionais visitados e a partir das conversas com os beneficiários entrevistados. Normalmente, residenciais da tipologia horizontal não são contemplados com áreas de lazer ou convivência, o que direcionou as avaliações para os níveis inferiores de satisfação - evidência trazida também por Morais et al. (2014), no estudo em 23 empreendimentos, localizados nas cidades cearenses de Fortaleza, Aquiraz, Caucaia, Horizonte, Maracanaú, Maranguape, Itaitinga, Cascavel, Juazeiro do Norte e Sobral. A pesquisa nacional também constatou essa carência. Segundo o relatório "as recomendações para áreas de lazer eram menores" (Brasil, 2014, p.81) à época do levantamento.

Todavia, no caso da unidade vertical, em que a recomendação normativa diz que tais áreas devam ser providas, os entrevistados alegaram que o nível de qualidade dos equipamentos era ruim, sendo depreciado com pouco tempo de uso (argumentaram, em complemento, sobre o reduzido comprometimento das famílias com a conservação e manutenção das áreas). Outrossim, foi comentado a respeito da dificuldade de convivência em condomínio, desde situações como o pagamento das taxas e tarifas (novidade para a maioria dos beneficiados), até noções de higiene e cuidados com o patrimônio (possíveis resquícios de um histórico de convivência com condições de moradia precárias, insalubres e horizontais).

No que se refere a satisfação quanto a infraestrutura urbana, identificou-se que as médias de pontuações oscilaram em valores médios-altos (isto é, tendendo do valor médio ao valor máximo da escala de pontos). Um elemento deve ser destacado e diz respeito à tipologia. Houve relatos de insatisfação com o abastecimento de água, em apartamentos. Os beneficiários relataram que, na época da entrega das casas, foi providenciado um único registro geral para cada bloco de apartamentos. Caso algum morador deixasse de cumprir com as responsabilidades de pagamento das contas de água, o bloco inteiro seria penalizado. Nota-se, para esse caso, que o teste de médias 
ratificou a diferença entre os grupos, confirmando que os beneficiários da tipologia horizontal se apresentaram mais satisfeitos do que aqueles contemplados com apartamentos.

Entre as fases do Programa, a constatação foi de que houve acréscimos na satisfação, principalmente em variáveis como qualidade das calçadas e ruas, disponibilidade de sinal de telefonia, acessibilidade e aparência dos conjuntos habitacionais. Elementos esses que são incrementos ao longo do tempo no PMCMV, sendo que o teste de médias indicou que a fase II proporcionou melhor média de satisfação entre as famílias beneficiadas. As inovações são percebidas dada a promulgação de legislações e manuais por parte do governo. Um exemplo disso, como forma de regulamentar o provimento de benfeitorias aos empreendimentos, foi o lançamento da Portaria n. 146 (2016), pelo Ministério das Cidades que, além de atualizar as especificações mínimas das unidades habitacionais, aprova as especificações urbanísticas dos empreendimentos, com destaque para as áreas de lazer e uso comum dos conjuntos.

\subsection{Satisfação dos Beneficiários Quanto ao Entorno}

Após avaliação das dimensões mais tangíveis do provimento habitacional, é direcionado foco para a análise do entorno - as regiões limítrofes ou áreas próximas ao empreendimento e sua disponibilidade de equipamentos, serviços ou possibilidade de viabilização. Embora o menos palpável dentre os produtos, o entorno fornece a ligação com a cidade, com os serviços e os equipamentos urbanos, bem como a necessidade de oferta de transporte público. Os resultados, subdivididos em infraestrutura urbana e acesso, estão na Tabela 5.

Tabela 5:

Satisfação dos beneficiários em cada grupo e subcategorias do entorno

\begin{tabular}{|c|c|c|c|c|c|c|c|}
\hline \multirow{2}{*}{\multicolumn{2}{|c|}{ Grupos/Subcategoria }} & \multicolumn{3}{|c|}{ Infraestrutura Urbana } & \multicolumn{3}{|c|}{ Acesso } \\
\hline & & Média & Desvio Padrão & $\begin{array}{l}\text { Teste de } \\
\text { Médias }\end{array}$ & Média & Desvio Padrão & $\begin{array}{l}\text { Teste de } \\
\text { Médias }\end{array}$ \\
\hline \multirow{2}{*}{ Tipologia } & Horizontal & 3,18 & 0,88 & \multirow{2}{*}{$0,150 * *$} & 2,76 & 0,87 & \multirow[b]{2}{*}{$0,000 *$} \\
\hline & Vertical & 3,42 & 0,89 & & 3,49 & 0,65 & \\
\hline \multirow{2}{*}{ Fase do Programa } & Fase I & 3,15 & 1,06 & \multirow{2}{*}{$0,190 * *$} & 3,05 & 0,88 & \multirow{2}{*}{$0,290 * *$} \\
\hline & Fase II & 3,40 & 0,74 & & 3,23 & 0,82 & \\
\hline \multirow{4}{*}{$\begin{array}{l}\text { Tamanho da } \\
\text { Família }\end{array}$} & Até 2 pessoas & 3,64 & 1,04 & \multirow{3}{*}{$0,034 *$} & 3,44 & 0,58 & \multirow{3}{*}{$0,036^{*}$} \\
\hline & Entre 3 a 5 & 3,30 & 0,83 & & 3,09 & 0,94 & \\
\hline & Acima de 6 & 2,94 & 0,78 & & 2,88 & 0,67 & \\
\hline & a de Cronbach ${ }^{a}$ & & 0,717 & & & 0,826 & \\
\hline
\end{tabular}

Nota. Dados obtidos na aplicação de questionários com escala do tipo Likert de 05 pontos, sendo 01 a pontuação mínima e 05 corresponde a pontuação máxima. Fonte: resultados da pesquisa.

${ }^{a}$ O Alfa de Cronbach valida a formação das subcategorias por apresentar valores superiores a 0,60.

* valores significativos ao nível de $5 \%$; **Não significativo.

Sobre a infraestrutura urbana, observa-se que as médias de satisfação não se diferenciaram no que diz respeito à tipologia e à fase do Programa. Ou seja, de acordo com a avaliação, os beneficiários demonstraram satisfação na faixa mediana da escala de pontos. A não diferenciação entre os grupos relativos às fases não permite evidenciar se houve melhorias quanto a infraestrutura urbana do entorno e no que tange ao acesso aos principais equipamentos e serviços disponibilizados na cidade, uma vez que as satisfações médias foram estatisticamente iguais.

Já na subcategoria acesso, os moradores de unidades habitacionais sob a forma horizontal, mostraram insatisfação com a ligação do conjunto aos principais pontos do entorno. Esse resultado foi reforçado com a diferenciação entre os grupos, atestada pelo teste de médias. A explicação para o resultado advém da localização dos empreendimentos constituídos sob esta tipologia: tais áreas demandam maior espaço para edificação das unidades (construção horizontalizada) e a maioria dos municípios visitados não possuía territórios próximos a áreas centrais para atenderem tais necessidades. Portanto, como resultado, os residenciais tendem a ser construídos em áreas longínquas, o que pode diminuir a satisfação dos beneficiários quanto ao acesso aos serviços e aos equipamentos disponíveis na cidade. Sobre a disponibilidade de terrenos, é oportuno comentar sobre a auditoria encomendada pelo Tribunal de Contas da União [ TCU] (2016) à Organização Latino Americana e do Caribe das Entidades Fiscalizadoras Superiores.

[ ...] O tribunal identificou que a quantidade de unidades habitacionais construídas nas capitais e em algumas regiões metropolitanas foi significativamente inferior à esperada. As dificuldades encontradas dizem respeito a pouca oferta de terrenos e ao valor dos mesmos, o que acaba por desestimular as empresas em adquiri-los (TCU, 2016). 
Outro resultado que despertou atenção foi a diminuição da satisfação com a infraestrutura urbana do entorno e o acesso de acordo com o aumento do número de integrantes na família. A inferência que se faz diz respeito ao fato de que famílias numerosas tendem a ter uma composição mais heterogênea (adultos, idosos, crianças e adolescentes) o que demanda mais (e diversificados) equipamentos públicos e serviços (saúde, creche, educação, lazer, transporte, comércio e serviços em geral) para atendimento das necessidades que, devido à localização do empreendimento, podem estar distantes e/ou em bairros mais afastados. O comportamento médio das variáveis para os grupos de tamanho familiar reafirmou o resultado de insatisfação para ambas as subcategorias: à exceção do acesso à educação, todas as variáveis relacionadas ao entorno, famílias com 06 ou mais pessoas registraram as menores médias de satisfação.

Conforme também ressaltado nesta avaliação, a localização é um aspecto bastante debatido na literatura. Em outras pesquisas sobre empreendimentos do PMCMV, averiguou-se aspectos referentes ao processo de periferização dos conjuntos habitacionais. As análises nas metrópoles de Goiânia (Moysés, Cunha, Borges \& Maia, 2013) e Belém (Lima, Ponte, Rodrigues, Neto \& Melo, 2013) identificaram processos similares com a extensão do tecido urbano para áreas rurais ou periurbanas, nas quais os equipamentos e serviços (públicos ou não) eram precários ou inexistentes. Na investigação de Morais et al. (2014), os beneficiários expuseram insatisfação com acesso a serviços em geral, lazer, comércio, transporte público e o acesso ao próprio condomínio. E na pesquisa nacional do PMCMV, a avaliação das famílias com relação a inserção urbana não foi positiva, sendo os principais pontos críticos a disponibilidade de equipamentos de saúde, escolas e creches e as distâncias dos empreendimentos dos centros das cidades.

\subsection{Afinal, Estão Satisfeitos Os Beneficiários do Programa Minha Casa, Minha Vida?}

A melhor resposta à pergunta que dá título à essa subseção é: os beneficiários demonstraram estar satisfeitos com determinados aspectos e insatisfeitos com outros. Nessa perspectiva, em resumo, os resultados nos permitiram fazer as seguintes considerações e comparações: em relação a unidade habitacional, os beneficiários de moradias horizontais manifestaram maior satisfação do que os da tipologia vertical; famílias mais numerosas exibiram satisfação inferior (principalmente no que diz respeito a habitabilidade) e a segunda fase do Programa foi mais bem avaliada (refletindo a satisfação quanto as inovações incorporadas à construção das casas). Sobre o conjunto habitacional, beneficiários dos empreendimentos verticais, com número reduzido de integrantes e de contratações da segunda fase, revelaram-se mais satisfeitos. E quanto ao entorno, foi percebida a diminuição da satisfação quanto à infraestrutura da vizinhança e acesso à cidade conforme o aumento do tamanho da família. Resultados encontrados em outros estudos sobre o PMCMV, e também neste em especial, denotam que as percepções dos beneficiários foram melhores quanto aos atributos da unidade habitacional (Brasil, 2014; Morais et al., 2014; Moreira \& Silveira, 2015) em detrimento de outras dimensões analisadas.

Por consequência, elementos em particular que esta avaliação identifica e que requerem atenção dos formulares do Programa vão ao encontro do número de integrantes das famílias, uma vez que as mais numerosas apresentaram menor satisfação quanto aos diversificados atributos dos produtos entregues. Além disso, destaca-se a insatisfação quanto a segurança. Tal situação pode ser entendida como uma externalidade negativa do PMCMV, o que conota aos residenciais características pejorativas, como "periferia", "lugar perigoso", "região foco de tráfico de drogas", o que proporciona sentimento de desconforto nos beneficiários, sendo unânime a sensação de insegurança, independente da característica do Programa ou da família. Ademais, a localização dos empreendimentos é um problema persistente nas intervenções habitacionais: a inserção urbana e a ligação com a cidade ficam comprometidas devida a construção dos residenciais em regiões de urbanização não consolidadas.

É válido mencionar ainda que ao trazer a perspectiva do beneficiário para a avalição, as discussões caminharam na direção de mesclar a medição de aspectos físico-construtivos (tamanho dos cômodos, estrutura, materiais) com os subjetivos (privacidade, barulhos/ruído, relação com a vizinhança) no tocante aos principais produtos entregues pelo Programa. Em muitos casos e justamente pela gênese da intervenção (que diz respeito a construção de novas casas), fixa-se numa visão estrita da unidade habitacional em seus aspectos materiais. Mas mereceu destaque, também, em consonância a Marengo e Elorza (2010), Kowaltowski e Granja (2011) e Hernández e Velásquez (2014) outras dimensões do "morar", principalmente àquelas subjetivas aos envolvidos. 


\section{Considerações Finais}

O estudo descrito e discutido ao longo das páginas anteriores teve sua tradição ancorada na avaliação de políticas públicas. A análise compreendeu a iniciativa do governo Federal brasileiro para enfrentamento dos problemas habitacionais do país: o Programa Minha Casa, Minha Vida, considerando o critério da satisfação dos beneficiários. A investigação buscou avaliar os resultados do Programa, haja vista a percepção daquelas que são as mais afetadas pela intervenção: as famílias beneficiadas. Assim, com base em seu corpo normativo e em estudos correlatos, três categorias de análise foram estabelecidas: unidade habitacional, conjunto habitacional e entorno. Oito municípios do estado de Minas Gerais foram selecionados para pesquisa in loco com as famílias. Para imprimir um processo de medição sistemática mais dinâmico, foram incorporadas características contextuais do Programa e das famílias, o que permitiu identificar a satisfação em função de aspectos particulares, tais como: a fase do PMCMV, a tipologia das casas e o tamanho familiar.

É considerável reforçar, nesta perspectiva, a relevância dos estudos avaliativos para o campo da Administração Pública. O "Minha Casa, Minha Vida" é resultado da mente dos formuladores de políticas públicas e, no momento de sua concepção, pode-se acabar desconsiderando aspectos que pudessem ser merecedores de atenção. Em outras palavras, o Programa pode falhar e, por isso, deve ser corrigido, o que o faz ganhar novos delineamentos e tudo isso no decorrer de sua implementação. Dessa forma, a avaliação pode subsidiar decisões a respeito da continuidade, aperfeiçoamento e responsabilização dos agentes, colocando-a como valiosa ferramenta de gestão; além de poder informar aos usuários e/ou beneficiários e promover visibilidade à sociedade em geral sobre seu desempenho e impactos, o que torna este processo um instrumento de accountability.

Ademais, para além da execução dos programas sociais, há a continuidade na vida de quem teve sua realidade interferida e transformada. Um programa, como o caso do habitacional aqui analisado, termina quando as casas são entregues? Aparentemente, talvez. Mas o provimento habitacional é apenas o começo da transformação nas vidas de muitas famílias que são beneficiadas. O lar é o primeiro passo, garantir abrigo, proteção e moradia digna. Além de fazer valer o direito de ser cidadão e garantir o acesso à cidade. Porém, quando o Programa assume como sua diretriz a provisão de unidades habitacionais capazes de promover a sustentabilidade social, econômica e ambiental dos empreendimentos, a intervenção não termina após a edificação dos residenciais. Não é questão de delegar ao PMCMV a incumbência de realizar as demais iniciativas para garantir esses anseios. A questão é buscar mecanismos para executá-las, articular a intervenção com as demais políticas públicas e trazer para esse novo espaço da cidade, a cidade em si e tudo aquilo que todos os cidadãos circunscritos no município têm direito. É uma questão de planejamento e alinhamento das políticas urbanas e habitacionais.

É apropriado ressaltar, ainda, os desafios e limitações encontrados na condução da pesquisa. A avaliação in loco é uma atividade custosa, tanto em termos econômicos quanto de tempo para execução. Requer o envolvimento de diferentes indivíduos (pesquisadores, gestores públicos, facilitadores, beneficiários) e uma equipe preparada para cumprimento da proposta de trabalho.

E, por fim, é pertinente comentar sobre a incorporação da percepção dos beneficiários no processo de avaliação, uma vez que é fundamental consultar aqueles que de fato usufruem dos produtos entregues e vivenciam seus resultados e implicações. Além disso, foi possível observar que os atributos do contexto avaliado também importam e podem influenciar nas percepções. A partir disso, indicamos que sejam realizadas avaliações comparativas que compreendam outras características, sendo do contexto do Programa (como a estratificação em modalidades, regiões ou localidades específicas) ou dos beneficiários (em termos de gênero, nível de renda e outras especificidades da composição da família). Em especial, vislumbra-se como possibilidade futura a triangulação dos pontos de vista dos demais atores envolvidos para que se possa proporcionar um estudo mais amplo e que dê voz a todos os responsáveis pelo provimento habitacional à população de interesse social.

Por fim, em virtude do contato com os beneficiários, ficou nítida a importância social do PMCMV e a modificação que promove na vida da população atendida. Assim, é necessário, com base nos pontos críticos levantados, continuar realizando correções na execução do "Minha Casa, Minha Vida" para que as benfeitorias promovidas possam dirimir de fato as desigualdades sociais brasileiras.

\section{Notas}

1. Foi utilizado o método de Ward como algoritmo de hierarquização dos grupos e a medida de similaridade empregada foi a Distância Euclidiana ao Quadrado (Hair et al., 2005). Para 
Estariam satisfeitos os beneficiários do programa minha casa, minha vida? Evidências empíricas em municípios do Estado de Minas Gerais

determinação dos clusters foi considerado um conjunto de variáveis que relacionam habitação, comportamento demográfico e desenvolvimento socioeconômico.

2. Estratégia também adotada por Andrade (2015), Drumond (2014) e Santos (2014), em pesquisas envolvendo a perspectiva de beneficiários de políticas públicas habitacionais.

3. Dentre as variadas definições para a verticalização urbana, há as assertivas de Souza (1994) e Somekh (1997), citadas por Oliveira (2013), que a definem-na como sendo o resultado da multiplicação do solo urbano a partir do uso de diversas estratégias empreendidas pelos agentes detentores dos capitais fundiário, produtivo, imobiliário e financeiro. A materialização desse processo ocorre por intermédio do edifício. Há de se destacar que a tradição em examinar tal fenômeno advém das áreas de Arquitetura e Urbanismo e Geografia Urbana

\section{Referências}

Abiko, A. K. (1995). Introdução à gestão habitacional. São Paulo: EPUSP.

Amore, C. S., Shimbo, L. Z. \& Rufino, M. B. C. (Ed.). (2015). Minha casa... e a cidade? Avaliação do Programa Minha Casa, Minha Vida em seis estados brasileiros. Rio de Janeiro: Letra Capital.

Andrade, A. R. (2015). Análise da implementação do Programa Nacional de Habitação Rural em municípios da microrregião e Viçosa - MG. Dissertação de mestrado, Universidade Federal de Viçosa, Viçosa, MG, Brasil.

Aragão, D. L. L. J. de, \& Hirota, E. H. (2016). Sistematização de requisitos do usuário com o uso da Casa da Qualidade do QFD na etapa de concepção de unidades habitacionais de interesse social no âmbito do Programa Minha Casa, Minha Vida. Ambiente Construído, 16(4), 271-291.

Berr, L. R. \& Formoso, C. T. (2012). Método para avaliação da qualidade de processos construtivos em empreendimentos habitacionais de interesse social. Ambiente Construído, 12(2), 77-96.

Brasil (2004). Política Nacional de Habitação (Relatório Técnico/2004), Brasília, DF, Secretaria Nacional de Habitação, Ministério das Cidades.

Brasil (2010). Indicadores de Programas, Guia estratégico [ Manual]. Ministério do Planejamento, Secretaria de Planejamento e Investimentos Estratégicos.

Brasil (2014). Pesquisa de satisfação dos beneficiários do Programa Minha Casa, Minha Vida. (Relatório de Pesquisa/2014), Brasília, DF, Ministério das Cidades/Secretaria de Assuntos Estratégicos da Presidência da República, SNH; SAE-PR; IPEA.

Brasil (2015). Sistema Eletrônico do Serviço de Informação ao Cidadão. Ministério das Cidades. Recuperado em 20 fevereiro, 2015, de http://www.acessoainformacao.gov.br

Brasil. (2016). Minha Casa, Minha Vida: Resultados do Programa. Recuperado em 06 abril, 2016, de http://www.minhacasaminhavida.gov.br

Bryson, J. M., Patton, M. Q. \& Bowman, R. A. (2011). Working with evaluation stakeholders: a rationale, step-wise approach and toolkit. Evaluation and Program Planning, 34(1), 1-12.

Bugs, G. \& Reis, A. T. L. (2014). Avaliação da participação popular na elaboração de planos de habitação de interesse social no Rio Grande do Sul. Urbe - Revista Brasileira de Gestão Urbana, 6(2), 249-262.

Caixa Econômica Federal (n.d). Conceitos Orientadores para Concepção de Projetos de HIS. Recuperado em 20 fevereiro, 2015, de http://www.caixa.gov.br/site/paginas/downloads.aspx

Cardoso, A. L. (Ed.). (2013). O programa Minha Casa, Minha Vida e seus efeitos territoriais. Rio de Janeiro: Letra Capital.

Carraro, C. L. \& Dias, J. F. (2014). Diretrizes para prevenção de manifestações patológicas em Habitações de Interesse Social. Ambiente Construído, 14(2), 125-139.

Cervo, A. L. \& Bervian, P. A. (2002). Metodologia Científica (5a ed.). São Paulo: McGraw-Hill do Brasil. Cohen, E. \& Franco, R. (2008). Avaliação de projetos sociais (8a ed.). Petrópolis: Vozes.

Costa, C. C. M., Ferreira, M. A. M., Braga, M. J. \& Abrantes, L. A. (2012). Disparidades Inter-regionais e Características dos Municípios de Minas Gerais. Desenvolvimento em Questão, 10, 52-88. 
Costa, F. L. \& Castanhar, J. C. (2003). Avaliação de programas públicos: desafios conceituais e metodológicos. Revista de Administração Pública, 37(5), 969-992.

Drumond, A. M. (2014). Análise do Programa Lares Habitação Popular do Estado de Minas Gerais a partir da perspectiva do Policy Cycle. Dissertação de mestrado, Universidade Federal de Viçosa, Viçosa, MG, Brasil.

Frey, K. (2000). Políticas públicas: um debate conceitual e reflexões referentes à prática da análise de políticas públicas no Brasil. Planejamento e Políticas Públicas, 21, 211-259.

Fundação João Pinheiro. (2016). Déficit habitacional no Brasil 2013-2014. (Relatório de Pesquisa/2016), Belo Horizonte, MG, Centro de Estatísticas e Informações, Fundação João Pinheiro.

Gonçalves Junior, C. A., Dutra, R. de L., Lopes, R. L., \& Rodrigues, R. Lott. (2014). O impacto do Programa Minha Casa, Minha Vida na economia brasileira: uma análise de insumo-produto. Ambiente Construído, 14(1), 177-189.

Hair, JR., J. F., Anderson, R. E., Tatham, R. L. \& Black, W. C. (2005). Análise Multivariada de Dados (5a ed.). Porto Alegre: Bookman.

Hernández, G. \& Velásquez, S. (2014). Vivienda y calidad de vida: medición del hábitat social en el México Occidental. Bitácora, 24(1), 149-200.

Instituto Brasileiro de Geografia e Estatística (2010). Sinopse do Censo Demográfico 2010. Recuperado em 15 abril, 2015, em http://www.censo2010.ibge.gov.br/sinopse

Januzzi, P. M. (2005). Indicadores para diagnóstico, monitoramento e avaliação de programas sociais no Brasil. Revista do Serviço Público, 56(2), 137-160.

Kowaltowski, D, C. C. K. \& Granja, A. D. (2011). The concept of desire value as a stimulus for change in social housing in Brazil. Habitat International, 35(3), 435-446.

Lima, J. J. F., Ponte, J. P. X., Rodrigues, R. M., Neto, R. V. \& Melo, A. C. C. (2013). A promoção habitacional através do Programa Minha Casa Minha Vida na Região Metropolitana de Belém. In: Cardoso, A. L. (Org.). O programa Minha Casa, Minha Vida e seus efeitos territoriais (pp.161-185). Rio de Janeiro: Letra Capital.

Lima, L. P.; Formoso, C.T; Escheveste, M.E.S. (2011). Proposta de um protocolo para o processamento de requisitos do cliente em empreendimentos habitacionais de interesse social. Ambiente Construído, 11(2), 21-37.

Loureiro, M. R., Macário, V., \& Guerra, P. H. (2015). Legitimidade e efetividade em arranjos institucionais de políticas públicas: o Programa Minha Casa Minha Vida. Revista de Administração Pública, 49(6), 1531-1554.

Marengo, C. \& Elorza, A. L. (2010). Calidad de vida y políticas de hábitat. Programa de mejoramiento barrial em Córdoba, Argentina. Caso de estúdio: Barrio Malvinas Argentinas. Bitácora, 2(17), 79-94.

Maricato, E. (2009). Por um novo enfoque teórico na pesquisa sobre habitação. Cadernos Metrópole, 21, 33-52.

Maroco, J. \& Garcia-Marques, T. (2006). Qual a fiabilidade do alfa de Cronbach? Questões antigas e soluções modernas? Laboratório de Psicologia, 4(1), 65-90.

Moraes, O. B. \& Abiko, A. K. (2006, agosto). Utilização da análise fatorial para a identificação de estruturas de interdependência de variáveis em estudos de avaliação pós-ocupação. Anais do Encontro Nacional de Tecnologia no Ambiente Construído, Florianópolis, SC, Brasil, 11.

Morais, M. V., Carneiro, T. M. \& Barros Neto, J. de P. (2014, novembro). Projeto de habitação de interesse social: satisfação do usuário final. Anais do Encontro Nacional de Tecnologia do Ambiente Construído. Maceió, AL, Brasil, 15.

Moreira, V. S. \& Silveira, S. F. R. (2015). Indicadores de desempenho do Programa Minha Casa, Minha Vida: avaliação com base na satisfação dos beneficiários. Cadernos Gestão Pública e Cidadania, 20(66), 94-117.

Moreira, V. S. (2016). Avaliação dos Resultados do Programa "Minha Casa, Minha Vida" em Minas Gerais. Dissertação de mestrado, Universidade Federal de Viçosa, Viçosa, MG, Brasil.

Morra-Imas, L. G. \& Rist, R. C. (2009). The road to results: designing and conducting effective development evaluations. Washington: The World Bank. 
Moura, J. M. de. (2014). O Programa Minha Casa, Minha Vida na Região Metropolitana de Natal: uma análise espacial dos padrões de segregação e desterritorialização. urbe. Revista Brasileira de Gestão Urbana, 6(3), 339-359.

Moysés, A., Cunha, D. F., Borges, E. M., \& Maia, T. C. B. (2013). Impactos da produção habitacional contemporânea na Região Metropolitana de Goiânia: dinâmica, estratégias de mercado e a configuração de novas espacialidades e centralidades. In: Cardoso, A.L (Org.). O programa Minha Casa, Minha Vida e seus efeitos territoriais (pp.255-278). Rio de Janeiro: Letra Capital.

Oliveira, G. A. (2013). Verticalização urbana em cidades médias: o caso de Santa Cruz do Sul - RS. Boletim Gaúcho de Geografia, 40(2), 199-218.

Ortiz, A. M. L. \& Doménech, S. J. M. (2004). Algunos factores físicos y psicológicos relacionados con la habitabilidad interna de la vivenda. Medio Ambiente y Comportamiento Humano, 5(1), 89-113.

Pequeno, R., \& Rosa, S. V. (2016). O Programa Minha Casa Minha Vida na Região Metropolitana de Fortaleza-CE: análise dos arranjos institucionais. Cadernos Metrópole, 18(35), 191-216.

Pestana, M. H \& Gageiro, J. N. (2005). Análise de dados para ciências sociais a complementaridade do SPSS. (4a ed.). Lisboa: Sílabo.

Portaria n. 146, de 26 de abril de 2016 (2016). Dispõe sobre as diretrizes para a elaboração de projetos e aprova as especificações mínimas da unidade habitacional e as especificações urbanísticas dos empreendimentos destinados à aquisição e alienação com recursos advindos da integralização de cotas no Fundo de Arrendamento Residencial - FAR, e contratação de operações com recursos transferidos ao Fundo de Desenvolvimento Social - FDS, no âmbito do Programa Minha Casa, Minha Vida - PMCMV. Diário Oficial da União. Brasília, DF.

Portaria n. 168, de 12 de abril de 2013. Dispõe sobre as diretrizes gerais para aquisição e alienação de imóveis com recursos advindos da integralização de cotas no Fundo de Arrendamento Residencial - FAR, no âmbito do Programa Nacional de Habitação Urbana - PNHU, integrante do Programa Minha Casa, Minha Vida - PMCMV. Diário Oficial da União. Brasília, DF.

Ramires, J. C. L. (1998). O processo de verticalização das cidades brasileiras. Boletim de Geografia, 16(1), 97-106.

Ramos, M. P. \& Schabbach, L. M. (2012), O estado da arte da avaliação de políticas públicas: conceituação e exemplos de avaliação no Brasil. Revista de Administração Pública, v. 46, n.5, pp. 1271-294.

Reis, F. N. S. C., Silveira, S. F. R. \& Moreira, V. S. (2015). Resultados do Programa Minha Casa Minha Vida sob a Percepção dos Beneficiários. RACE, Revista de Administração, Contabilidade e Economia, 14(3), 925-956.

Richardson, R. J. (1999). Pesquisa Social: métodos e técnicas. São Paulo: Atlas.

Rolnik, R., Pereira, A. L. dos S., Moreira, F. A., Royer, L. de O., lacovini, R. F. G., \& Nisida, V. C. (2015). O Programa Minha Casa Minha Vida nas regiões metropolitanas de São Paulo e Campinas: aspectos socioespaciais e segregação. Cadernos Metrópole, 17(33), 127-154.

Romero, M. A. \& Ornstein, S. W. (2003). Avaliação Pós-ocupação: Métodos e Técnicas Aplicados à Habitação Social (Coleção Habitare). Porto Alegre: ANTAC.

Rossi, P. H., Lipsey, M.W. \& Freeman, H. E. (2004). Evaluation: a systematic approach (7a ed.). Thousand Oaks, CA: Sage.

Santos, S. N. (2014). Realidade, significado e expectativas do Programa Nacional de Habitação Rural: o caso de Guiricema e São Miguel do Anta - MG. 2014. 167 f. Dissertação de mestrado, Universidade Federal de Viçosa, Viçosa, MG, Brasil.

Schäfer, E. F. \& Gomide, F. P. B. (2014). Avaliação Pós-Ocupação do conjunto habitacional Moradias União Ferroviária Bolsão Audi/União, Curitiba (PR). Engenharia Sanitária e Ambiental, 19(2), 155-164.

Scheidt, F. S. S., Silva, P. R., Silva, S. M. C. P. \& Hirota, E. H. (2010). Consideração de requisitos ambientais em empreendimentos habitacionais de interesse social: um estudo de caso. Ambiente Construído, 10(1), 91-106.

Silva, C. F. \& Alves, T. W. (2014). Dinâmica dos financiamentos habitacionais nos municípios do Rio Grande do Sul de 2006 a 2010: uma avaliação do Programa "Minha Casa, Minha Vida". Revista de Administração Pública, 48(1), 7-54. 
Silva, J. M. P. (2011). Habitação de interesse social e as legislações municipais da região metropolitana de Campinas. Ambiente Construído, 11(3), 55-71.

Soares, I. O., Carvalho, A. W. B., Ribeiro Filho, G. B., \& Pinto, N. M. de A. (2013). Interesses especulativos, atuação do Estado e direito à cidade: o caso do programa "Minha Casa Minha Vida" em Uberaba (MG). Urbe, Revista Brasileira de Gestão Urbana, 5(1), 119-131.

Somekh, N. (1997). A cidade vertical e o urbanismo modernizador. São Paulo: FAPESP.

Soraggi, A. C. M. \& Mendonça, J. G. (2013). O Programa Minha Casa Minha Vida em Juatuba/MG: ampliação do mercado da moradia no espaço metropolitano periférico. In: Cardoso, A.L (Org.). $O$ programa Minha Casa, Minha Vida e seus efeitos territoriais (pp.93-113). Rio de Janeiro: Letra Capital.

Souza, C. (2006). Políticas Públicas: uma revisão da literatura. Sociologias, 16, 20-45.

Subirats, J., Knoepfel, P., Larrue, C. \& Varone, F. (2008). Análisis y gestión de políticas públicas. Barcelona, Espanha: Ariel.

Thery, H. (2017). Novas Paisagens Urbanas do Programa Minha Casa, Minha Vida. Mercator, 16, 114.

Tribunal de Contas da União. (2016). Relatório do TCU aponta falhas no Programa Minha Casa Minha Vida. Recuperado em 26 novembro 2016, de http://portal.tcu.gov.br/imprensa/noticias/relatorio-dotcu-aponta-falhas-no-programa-minha-casa-minha-vida.htm

Triola, M. F. (2005). Introdução à Estatística (9a ed.). Rio de Janeiro: LTC.

Unicef (1990). A UNICEF guide for monitoring and evaluation: making a difference? [ Manual]. Unicef. New York, NY: US.

Vicentim, T. N., \& Kanashiro, M. (2016). Análise do comércio e dos serviços nos empreendimentos do Programa Minha Casa, Minha Vida (PMCMV): estudo de caso do Residencial Vista Bela - Londrina, PR. Ambiente Construído, 16(4), 227-250.

Weiss, C. (1998). Evaluation (2a ed.). New Jersey: Prentice Hall, Upper Saddle River.

Wu, X., Ramesh, M., Howlett, M. \& Fritzen, S. (2010). The public policy primer: managing the policy process. Routledge: New York. 